\title{
Red pitaya juice supplementation ameliorates energy balance homeostasis by modulating obesity-related genes in high- carbohydrate, high-fat diet-induced metabolic syndrome rats
}

\author{
Nurul Shazini Ramli ${ }^{1 *}$, Patimah Ismail ${ }^{2}$ and Asmah Rahmat ${ }^{3}$
}

\begin{abstract}
Background: Red pitaya (Hylocereus polyrhizus) or known as buah naga merah in Malay belongs to the cactus family, Cactaceae. Red pitaya has been shown to give protection against liver damage and may reduce the stiffness of the heart. Besides, the beneficial effects of red pitaya against obesity have been reported; however, the mechanism of this protection is not clear. Therefore, in the present study, we have investigated the red pitayatargeted genes in obesity using high-carbohydrate, high-fat diet-induced metabolic syndrome rat model.

Methods: A total of four groups were tested: corn-starch (CS), corn-starch + red pitaya juice (CRP), high-carbohydrate, high-fat (HCHF) and high-carbohydrate, high-fat + red pitaya juice (HRP). The intervention with $5 \%$ red pitaya juice was continued for 8 weeks after 8 weeks initiation of the diet. Retroperitoneal, epididymal and omental fat pads were collected and weighed. Plasma concentration of IL-6 and TNF-a were measured using commercial kits. Gene expression analysis was conducted using RNA extracted from liver samples. A total of eighty-four genes related to obesity were analyzed using PCR array.

Results: The rats fed HCHF-diet for 16 weeks increased body weight, developed excess abdominal fat deposition and down-regulated the expression level of $\mathrm{IL}-1 \mathrm{a}, \mathrm{IL}-1 \mathrm{r} 1$, and $\mathrm{Cn}$ tfr as compared to the control group. Supplementation of red pitaya juice for 8 weeks increased omental and epididymal fat but no change in retroperitoneal fat was observed. Red pitaya juice reversed the changes in energy balance homeostasis in liver tissues by regulation of the expression levels of Pomc and Insr. The increased protein expression levels of IL-6 and TNF-a in HCHF group and red pitaya treated rats confirmed the results of gene expression.
\end{abstract}

Conclusion: Collectively, this study revealed the usefulness of this diet-induced rat model and the beneficial effects of red pitaya on energy balance homeostasis by modulating the anorectic, orexigenic and energy expenditure related genes.

Keywords: Red pitaya juice, Obesity-related genes, Metabolic syndrome

\footnotetext{
*Correspondence: shazini@upm.edu.my

1 Department of Food Science, Universiti Putra Malaysia, Serdang, Selangor

43400, Malaysia

Full list of author information is available at the end of the article
} 


\section{Background}

The increasing incidence of obesity worldwide could result from complex interactions between environmental, genetic [1] and psychosocial factors [2]. The social-environmental influences such as reduced physical activity, increased sedentary behavior and increased accessibility of high-fat and energy-dense foods facilitate the obesity pandemic by disrupting the body's energy balance. Energy balance is defined as the difference between energy intake and energy expenditure including basal metabolism, physical activity and adaptive thermogenesis [2]. A state of positive energy balance will occur when energy intake exceeds energy expenditure, leading to increased storage of energy as adipose tissue. Genetic factors may also influence body weight by affecting one or more component (s) of energy balance [3].

The physiological control system for energy intake and body weight is complex and involves extensive changes of gene expression throughout the body. It is postulated that the central nervous system controls energy balance through several mechanisms. These include it influence on feeding and physical activity behavior, the regulation of the autonomic nervous system activities including metabolism, and changes in key hormones such as leptin, ghrelin, insulin, growth hormone, sex steroids, cortisol and thyroid hormones [1, 4-6]. Therefore, it is critical to understand the gut-brain interaction underlying the appetite and feeding regulation of energy balance to develop new pharmacogenetical strategy for obesity studies.

Red pitaya is a cactus fruit originating from Mexico. In Malaysia, this fruit is known as red dragon fruit or 'buah naga merah', possibly due to the scaly structure of the peel. The beneficial effects of red pitaya reported in laboratory animal studies could be due to its ability to increase antioxidant capacity and suppress oxidative stress damage [7-9]. Our previous study indicated that red pitaya supplementation ameliorated liver and cardiovascular damage induced by high-carbohydrate, high-fat feeding [10]. However, the effects of red pitaya supplementation on obesity along with its related mechanism not clear. Red pitaya supplementation increases energy intake without increasing body weight [10], so it is hypothesized that red pitaya may stimulate anorectic genes or down-regulate orexigenic genes to increase energy expenditure. Therefore, the present work determined the changes in anorectic and orexigenic genes as well as the inflammatory pathway in a rat model of diet-induced obesity following supplementation with red pitaya.

\section{Methods}

\section{Preparation of diet}

Red pitaya was obtained from Queensland Australia. The identification of the fruit has been done by a botanist from Biodiversity Unit, Institute of Biosciences, Universiti Putra Malaysia. The voucher number is SK-2440/14. The fruits were then cleaned, and the fruit pulp was squeezed using juice maker. Sample preparation was conducted in reduced light condition in order to minimize the pigment loss [10].

\section{Animals and diet}

The experimental protocols have been described in our previous publication [10]. In brief, the experimental groups consisted of 48 male Wistar rats (aged 8-9 weeks; weight $337 \pm 5$ g) supplied by and individually housed at The University of Southern Queensland animal house. All experimental groups were housed in a temperaturecontrolled, 12 hour light-dark cycle environment with ad libitum access to water and the group specific diet. Daily body weight, feed and water measurements were taken to monitor the day-to-day health of the rats and the results have been reported in our previous publication [10]. The rats were randomly divided into four groups based on their diet: corn starch (CS; $n=12)$; corn starch + red pitaya juice (CRP; $5 \%$ in the diet; $n=12$ ); high-carbohydrate, high-fat (HCHF; $n=12$ ); High-carbohydrate, high-fat + red pitaya juice (HRP; $n=12)$. Fructose $(25 \%)$ was added as drinking water for all high-carbohydrate, high-fat fed rats, while corn starch group was given normal water. The detailed macroand micro-nutrient composition of the CS and $\mathrm{HCHF}$ diets are reported in previous publications $[11,12]$. Red pitaya juice was administered for 8 weeks starting from 8 weeks after the initiation of the CS or HCHF diet. All the experimental protocols were approved by the Animal Experimentation Ethics Committee of The University of Southern Queensland under the guidelines of the National Health and Medical Research Council of Australia.

\section{Organ weights}

Terminal anaesthesia was induced via intraperitoneal injection of pentobarbitone sodium (Lethabarb, $100 \mathrm{mg} / \mathrm{kg}$ ). Heparin (Sigma-Aldrich Australia) was administered (100 IU) through the right femoral vein and blood (about $5 \mathrm{ml}$ ) was taken from the abdominal aorta. Immediately after the rats were killed, the abdominal fat mass as the retroperitoneal, epididymal and omental fat pads were collected. The organ weights were normalized to the tibial length at the time of their removal (in $\mathrm{mg} / \mathrm{mm}$ ).

\section{Visceral adiposity index}

Visceral adiposity index (\%) was calculated as: ([retroperitoneal fat $(\mathrm{g})+$ omental fat $(\mathrm{g})+$ epididymal fat $(\mathrm{g})] /[$ body weight $(\mathrm{g})]) \times 100$ and expressed as adiposity percent [12]

\section{Inflammatory markers}

Plasma concentrations of interleukin 6 (IL-6) and TNFalpha were quantified based on manufacturer's guidelines using commercially available ELISA kits. Plasma Creactive protein $(\mathrm{CRP})$ was estimated using a commercial 
kit according to the manufacturer-provided standards and protocol using a Roche/Hitachi cobas c system.

\section{Isolation of total RNA}

During terminal experiments, liver samples were collected and immediately stored at $-80{ }^{\circ} \mathrm{C}$ freezer. Total RNA from corn starch (CS), corn starch + red pitaya (CRP), highcarbohydrate, high-fat (HCHF) and high-carbohydrate, high-fat + red pitaya (HRP) groups was isolated from liver samples using RNeasy ${ }^{\circ}$ plus mini kit (Qiagen, Valencia, CA) according to manufacturer's protocol. Three replicates were analyzed for each group (CS, CRP, HCHF and HRP). Basically, $25 \mathrm{mg}$ liver samples were excised and immediately homogenized in Buffer RLT plus. The genomic DNA was removed and purified from the lysate liver sample. Finally, the RNeasy spin column was placed into a new $2 \mathrm{~mL}$ collection tube and centrifuged at $12000 \mathrm{rpm}$ for 1 minute. The $2 \mathrm{~mL}$ collection tube was then discarded. The RNA bound at the RNeasy spin column was eluted in a new $1.5 \mathrm{~mL}$ collection tube with $40 \mu \mathrm{L}$ RNase-free water and centrifuged at $12000 \mathrm{rpm}$ for 1 minute. The concentration of extracted RNA from the samples was determined by measuring at $260 \mathrm{~nm}$ using a Nano-Drop 1000 Spectrophotometer (Thermo Scientific, Waltham, MA). In brief, $1 \mu \mathrm{L}$ of RNase-free water was added to pedestal for blank sample. Then, $1 \mu \mathrm{L}$ of RNA sample was added. The integrity of extracted RNA sample was measured using Bioanalyzer (Agilent's RNA 6000 Nano kit).

CDNA synthesis for real-time Reverse Transcription- (RT) PCR cDNA was prepared using $\mathrm{RT}^{2}$ profiler $\mathrm{PCR}$ array first strand kit based on manufacturer's instructions. Briefly, genomic DNA elimination mix was prepared by mixing RNA (volume varies based on the concentration obtained), $2 \mu \mathrm{L}$ of gDNA elimination buffer and RNasefree water to form a total volume of $10 \mu \mathrm{L}$. The mixture was mixed by gently pipetting and the genomic DNA elimination mix was then incubated for 5 minutes at $42{ }^{\circ} \mathrm{C}$. It was immediately placed on ice for at least $1 \mathrm{mi}-$ nute. The reverse-transcription mix was prepared according to manufacturer's guidelines. Ten $\mu \mathrm{L}$ of reversetranscription mix was added to tube containing $10 \mu \mathrm{L}$ genomic DNA elimination mix, and incubated at $42{ }^{\circ} \mathrm{C}$ for exactly 15 minutes. The reaction was stopped by incubating at $95{ }^{\circ} \mathrm{C}$ for 5 minutes to inactivate the reverse transcriptase. The $20 \mu \mathrm{L}$ of cDNA synthesis reaction mixture was mixed with $91 \mu \mathrm{L}$ of RNase-free water making a total $111 \mu \mathrm{L}$ of reaction mixture. The reaction mixture was placed on ice until further use.

\section{Array-based SYBR ${ }^{\oplus}$ Green RT-PCR}

The constitutive gene expression profiling was conducted using to $\mathrm{RT}^{2}$ profiler PCR array related to obesity signal transduction according to manufacturer's protocols. The gene array profiled the expression of 84 genes including orexigenic genes, anorectic genes, and related to energy expenditure (Table 1, PARN-017Z-12, RT ${ }^{2}$ Profiler $^{\text {rat }}$ PCR Array Rat Obesity). The array included the controls for human genomic DNA contamination, reverse-transcription, positive PCR control, and 5 housekeeping genes to normalize the relative gene expression for analysis of data. The five housekeeping genes were ribosomal protein large P1 (Rp1p1), hypoxanthine phosphoribosyltransferase 1 (Hprt1), ribosomal protein L13A (Rp113a), lactate dehydrogenase A (Ldha), and $\beta$-actin (Actb). The PCR components mix were prepared with $1150 \mu \mathrm{L}$ of $2 \times \mathrm{RT}^{2}$ SYBR Green ROX FAST mastermix, $102 \mu \mathrm{L}$ of cDNA synthesis reaction, and $1048 \mu \mathrm{L}$ of RNase-free water combined making a total volume of $2300 \mu \mathrm{L}$. Then, the $\mathrm{RT}^{2}$ profiler PCR array was removed from its sealed bag, and the array was slid into the Rotor-Disc 100 Loading Block using the tab position A1 and the tube guide holes. Twenty $\mu \mathrm{L}$ of PCR component mix was pipetted into each well of the $\mathrm{RT}^{2}$ profiler PCR array. For each sample, the $\mathrm{RT}^{2}$ profiler PCR array was conducted in triplicate.

Real time PCR was performed using a two-step cycling program on rotor gene real time PCR machine (Qiagen, Valencia, CA): $10 \mathrm{~min}$ at $95{ }^{\circ} \mathrm{C}$ (cycle 1) followed by 40 cycles of $15 \mathrm{~s}$ at $95{ }^{\circ} \mathrm{C}$ and $1 \mathrm{~min}$ at $60{ }^{\circ} \mathrm{C}$. SYBR green fluorescence was detected and recorded. The threshold cycle (CT) above the background for each reaction was then calculated.

\section{Statistical analysis}

Data for organ weights, and inflammatory markers were analyzed using GraphPad Prism version 5.00 for Windows (San Diego, CA, USA). All data were presented as mean \pm SEM. All group data were tested for variance using Bartlett's test. Variables that were not normally distributed were transformed (using log 10 function) prior to statistical analysis. The effects of diet, treatment and their interactions were tested by two-way analysis of variance. When interaction and/or the main effects were significant, means were compared using Newman-Keuls multiple-comparison post hoc test. A nonparametric test, the Kruskal-Wallis test, was performed when transformations did not result in normality or constant variance. The gene expression data was analyzed using $\mathrm{RT}^{2}$ Profiler PCR Array Data analysis version 3.5 from SABiosciences website. All data were normalized by one housekeeping gene (endogenous control). The fold change among the groups were obtained from $\Delta \Delta \mathrm{CT}$. $\Delta \mathrm{CT}$ was defined as the value of subtracting the $\mathrm{CT}$ value of endogenous control from the CT value of the target messenger RNA (mRNA). Student's $t$ test was used to determine the differences in gene expression. The significant values were considered at the level of $p<0.05$. 
Table 1 The symbol and description of genes in the PCR array

\begin{tabular}{|c|c|c|c|}
\hline Position & Symbol & Description & Gene Name \\
\hline $\mathrm{A} 01$ & Adcyap1 & Adenylate cyclase activating polypeptide 1 & Pacap \\
\hline $\mathrm{A} 02$ & Adcyap1r1 & Adenylate cyclase activating polypeptide 1 receptor 1 & PACAP-R1A, PACAPR1, PACAPR1A \\
\hline $\mathrm{A} 03$ & Adipoq & Adiponectin, C1Q and collagen domain containing & Acdc, Acrp30 \\
\hline $\mathrm{A} 04$ & Adipor1 & Adiponectin receptor 1 & - \\
\hline A05 & Adipor2 & Adiponectin receptor 2 & - \\
\hline A06 & Adra2b & Adrenergic, alpha-2B-, receptor & - \\
\hline $\mathrm{A} 07$ & Adrb1 & Adrenergic, beta-1-, receptor & B1AR,RATB1AR \\
\hline A08 & Agrp & Agouti related protein homolog (mouse) & - \\
\hline A09 & Apoa4 & Apolipoprotein A-IV & Apo-AIV, ApoA IV, apoAIV \\
\hline A10 & Atrn & Attractin & - \\
\hline A11 & Bdnf & Brain-derived neurotrophic factor & MGC105254 \\
\hline $\mathrm{A} 12$ & Brs3 & Bombesin-like receptor 3 & - \\
\hline B01 & C3 & Complement component 3 & - \\
\hline B02 & Calca & Calcitonin-related polypeptide alpha & CAL6, CGRP, Cal1, Calc, RATCAL6, calcitonin \\
\hline B03 & Calcr & Calcitonin receptor & - \\
\hline B04 & Cartpt & CART prepropeptide & Cart \\
\hline B05 & Cck & Cholecystokinin & - \\
\hline B06 & Cckar & Cholecystokinin A receptor & Cck-ar \\
\hline B07 & Clps & Colipase, pancreatic & COLQ \\
\hline B08 & Cnr1 & Cannabinoid receptor 1 (brain) & SKR6R \\
\hline B09 & Cntf & Ciliary neurotrophic factor & - \\
\hline B10 & Cntfr & Ciliary neurotrophic factor receptor & - \\
\hline B11 & Crh & Corticotropin releasing hormone & CRF \\
\hline B12 & Crhr1 & Corticotropin releasing hormone receptor 1 & - \\
\hline $\mathrm{C} 01$ & Drd1a & Dopamine receptor D1A & D1a, Drd-1, Drd1 \\
\hline $\mathrm{CO2}$ & Drd2 & Dopamine receptor D2 & - \\
\hline $\mathrm{CO3}$ & Gal & Galanin prepropeptide & Galn \\
\hline $\mathrm{CO4}$ & Galr1 & Galanin receptor 1 & Galnr1 \\
\hline C05 & Gcg & Glucagon & GLP-1 \\
\hline $\mathrm{C06}$ & Gcgr & Glucagon receptor & MGC93090 \\
\hline $\mathrm{CO}$ & Gh1 & Growth hormone 1 & Gh,RNGHGP \\
\hline $\mathrm{C08}$ & Ghr & Growth hormone receptor & GHR, BP, MGC12496, MGC156665 \\
\hline $\mathrm{CO9}$ & Ghrl & Ghrelin/obestatin prepropeptide & - \\
\hline $\mathrm{C} 10$ & Ghsr & Growth hormone secretagogue receptor & - \\
\hline $\mathrm{C} 11$ & Glp1r & Glucagon-like peptide 1 receptor & Glip, RATGL1RCP \\
\hline $\mathrm{C} 12$ & Grp & Prolactin releasing hormone receptor & Gpr10, Uhr-1 \\
\hline D01 & Grpr & Melanin-concentrating hormone receptor 1 & Gpr24, Mch-1r, Slc1 \\
\hline D02 & HcRt & Hypocretin & orexin-A \\
\hline D03 & Hertr1 & Hypocretin (orexin) receptor 1 & Hctr1 \\
\hline D04 & Hrh1 & Histamine receptor $\mathrm{H} 1$ & Hisr \\
\hline D05 & $\mathrm{Htr} 2 \mathrm{C}$ & 5-hydroxytryptamine (serotonin) receptor 2 C $1 \mathrm{C}$ & 5-HT2C, 5-HTR2C, 5HT- \\
\hline D06 & lapp & Islet amyloid polypeptide & - \\
\hline D07 & $\mathrm{IL}-1 \mathrm{a}$ & Interleukin 1 alpha & IL-1 alpha \\
\hline D08 & $\mathrm{IL}-1 \mathrm{~b}$ & Interleukin 1 beta & - \\
\hline
\end{tabular}


Table 1 The symbol and description of genes in the PCR array (Continued)

\begin{tabular}{|c|c|c|c|}
\hline D09 & $\mid \mathrm{L}-1 \mathrm{r} 1$ & Interleukin 1 receptor, type I & - \\
\hline D10 & IL-6 & Interleukin 6 & ILg6, Ifnb2 \\
\hline D11 & $\mathrm{IL}-6 \mathrm{r}$ & Interleukin 6 receptor & IL6R1, \|6ra, I|6r \\
\hline D12 & Ins1 & Insulin 1 & - \\
\hline E01 & Ins2 & Insulin 2 & - \\
\hline E02 & Insr & Insulin receptor & - \\
\hline E03 & Lep & Leptin & OB, obese \\
\hline E04 & Lepr & Leptin receptor & $\mathrm{Fa}$ \\
\hline E05 & Mc3r & Melanocortin 3 receptor & $M C 3-R$ \\
\hline E06 & Mchr1 & Melanin-concentrating hormone receptor 1 & Gpr24, Mch-1r, Slc1 \\
\hline E07 & $\mathrm{Nmb}$ & Neuromedin & B RGD1562710 \\
\hline E08 & $\mathrm{Nmbr}$ & Neuromedin B receptor & NMB-R \\
\hline E09 & $\mathrm{Nmu}$ & Neuromedin U & - \\
\hline E10 & Nmur1 & Neuromedin $\mathrm{U}$ receptor 1 & Gpr66 \\
\hline E11 & Npy & Neuropeptide $Y$ & NPY02, RATNPY, RATNPY02 \\
\hline E12 & Npy $1 \mathrm{r}$ & Neuropeptide $Y$ receptor $Y 1$ & MGC109393, NPY-1 \\
\hline F01 & $\mathrm{Nr3c1}$ & Nuclear receptor subfamily 3 , group C, member 1 & GR, Gcr, Grl \\
\hline F02 & Ntrk1 & Neurotrophic tyrosine kinase, receptor, type 1 & Trk \\
\hline F03 & Nts & Neurotensin & - \\
\hline F04 & Ntsr1 & Neurotensin receptor 1 & Ntsr \\
\hline F05 & Oprk1 & Opioid receptor, kappa 1 & - \\
\hline F06 & Oprm1 & Opioid receptor, mu 1 & MORA, Oprm, Oprrm1 \\
\hline F07 & Pomc & Proopiomelanocortin & Pomc1, Pomc2 \\
\hline F08 & Ppara & Peroxisome proliferator activated receptor alpha & PPAR \\
\hline F09 & Pparg & Peroxisome proliferator-activated receptor gamma & - \\
\hline F10 & Ppargcla & Peroxisome proliferator-activated receptor gamma, coactivator 1 alpha & Ppargc1 \\
\hline F11 & Prlhr & Prolactin Releasing Hormone Receptor & Prlhr \\
\hline F12 & Ptpn1 & Protein tyrosine phosphatase, non-receptor type 1 & MGC93562, Ptp \\
\hline G01 & Pyy & Peptide YY (mapped) & GHYY, RATGHYY, Yy, peptide-YY \\
\hline G02 & Ramp3 & Receptor (G protein-coupled) activity modifying protein 3 & - \\
\hline G03 & Sigmar1 & Sigma non-opioid intracellular receptor 1 & Oprs1 \\
\hline G04 & Sort1 & Sortilin 1 & $\mathrm{Nt3}, \mathrm{Nts3}$ \\
\hline G05 & Sst & Somatostatin & SS-14, SS-28, Smst \\
\hline G06 & Sstr1 & Somatostatin receptor 1 & Gpcrna \\
\hline G07 & Thrb & Thyroid hormone receptor beta & $\begin{array}{l}\text { C-erba-beta, ERBA2, Nr1a2, RATT3REC } \\
\text { T3rec, TRbeta }\end{array}$ \\
\hline G08 & Tnf & Tumor necrosis factor (TNF superfamily, member 2) & MGC124630, RATTNF, TNF-alpha, Tnfa \\
\hline G09 & Trh & Thyrotropin releasing hormone & THR, TRH01 \\
\hline G10 & Trhr & Thyrotropin releasing hormone receptor & - \\
\hline G11 & Ucn & Urocortin & - \\
\hline G12 & Ucp1 & Uncoupling protein 1 (mitochondrial, proton carrier) & MGC108736, Ucp, Ucpa, Uncp \\
\hline $\mathrm{H} 01$ & Actb & Actin, beta & Actx \\
\hline $\mathrm{H} 02$ & $\mathrm{~B} 2 \mathrm{~m}$ & beta-2-microglobulin & - \\
\hline $\mathrm{H} 03$ & Hprt1 & Hypoxanthine phosphoribosyltransferase 1 & Hgprtase, Hprt, MGC112554 \\
\hline $\mathrm{H} 04$ & Ldha & Lactate dehydrogenase A & Ldh1 \\
\hline
\end{tabular}


Table 1 The symbol and description of genes in the PCR array (Continued)

\begin{tabular}{llll}
\hline H05 & Rplp1 & Ribosomal protein, large, P1 & MGC72935 \\
H06 & RGDC & Rat Genomic DNA Contamination & RGDC \\
H07 & RTC & Reverse Transcription Control & RTC \\
H08 & RTC & Reverse Transcription Control & RTC \\
H09 & RTC & Reverse Transcription Control & RTC \\
H10 & PPC & Positive PCR Control & PPC \\
H11 & PPC & Positive PCR Control & PPC \\
H12 & PPC & Positive PCR Control & PPC \\
\hline
\end{tabular}

(Source: SABioscience, 2014)

\section{Results}

\section{Abdominal fats and visceral adiposity index}

An increase in retroperitoneal adipose tissue was observed in CRP but not in HRP compared to their respective nontreated controls (CS and HCHF groups) (Table 2). On the other hand, HRP group showed significant increase $(p<$ 0.05 ) in epididymal and omental fat deposition compared with CS and HCHF diet-fed rats (Table 2). No changes in visceral adiposity index were seen for red pitaya supplementation in high-carbohydrate, high-fat diet-fed rats (Table 2). On the other hand, CRP rats showed a trend of increasing visceral adiposity index but the differences were not significant $(p>0.05)$ (Table 2).

\section{Plasma inflammatory markers}

Results indicated that red pitaya supplementation significantly increased $(p<0.05)$ plasma concentration of TNF$\alpha$ and IL-6 (Table 2). There was no difference for CRP group for IL-6 concentration in comparison with CS-fed rats (Table 2). C-reactive protein, an acute phase reactant was increased with high-carbohydrate, high-fat feeding compared with corn starch fed control rats (Table 2). Red pitaya juice supplementation decreased C-reactive protein concentration in HRP rats as compared to controls rats (Table 2).

\section{Gene expression analysis}

\section{Concentration of extracted RNA}

Total RNA was successfully extracted from the liver tissues of HCHF, HRP CS, and CRP. For the best results from the $\mathrm{RT}^{2}$ Profiler PCR Array, all RNA samples should exhibit consistent quality and purity. High purity of RNA should have an $\mathrm{A}_{260} / \mathrm{A}_{280}$ reading between 1.8 and 2.0 and an $A_{260} / A_{230}$ reading should be greater than 1.7. On top of that, the concentration determined by $A_{260}$ should be greater than $40 \mu \mathrm{g} / \mathrm{mL}$. In the present study, all the samples fulfill the criteria indicating high purity of RNA.

\section{Gene expressions alterations}

The triplicate samples from each group produced reproducible results. Data analysis revealed that 14 genes (as measured by $\mathrm{CT}$ value) were detected while the remaining 71 genes were not detected and/or the genes were detected but the variation between the test sample and control is too great and thus the fold change results has to be validated further. Figure 1 shows the fold regulation

Table 2 Visceral adiposity index, abdominal fat, and plasma inflammatory markers in CS, CRP, HCHF and HRP diet-fed rats

\begin{tabular}{|c|c|c|c|c|c|c|c|}
\hline \multirow[t]{2}{*}{ Variable } & \multirow[t]{2}{*}{ CS } & \multirow[t]{2}{*}{ CRP } & \multirow[t]{2}{*}{$\mathrm{HCHF}$} & \multirow[t]{2}{*}{ HRP } & \multicolumn{3}{|l|}{$P$-value } \\
\hline & & & & & Diet & Treatment & Interaction \\
\hline Visceral adiposity index (\%) & $3.5 \pm 0.3^{b c}$ & $4.6 \pm 0.5^{b}$ & $6.6 \pm 0.6^{a}$ & $7.0 \pm 0.5^{a}$ & $<0.0001$ & 0.05 & 0.16 \\
\hline \multicolumn{8}{|c|}{ Abdominal fat, mg/mm tibial length } \\
\hline Retroperitoneal ( $n=7-8)$ & $118.9 \pm 12.9^{c}$ & $181.7 \pm 15.2^{b}$ & $303.7 \pm 26.6^{a}$ & $357.7 \pm 32.6^{a}$ & $<0.0001$ & 0.0217 & 0.0341 \\
\hline Omental $(n=7-8)$ & $102.5 \pm 7.3^{\mathrm{cd}}$ & $142.4 \pm 12.3^{\mathrm{cd}}$ & $173.9 \pm 44.0^{\mathrm{bc}}$ & $260.3 \pm 27.6^{a}$ & $<0.0001$ & 0.0141 & 0.27 \\
\hline Epididymal $(n=7-8)$ & $64.4 \pm 7.0^{\mathrm{cd}}$ & $101.3 \pm 11.4^{\mathrm{bd}}$ & $112.1 \pm 34.6^{\mathrm{bc}}$ & $191.0 \pm 13.9^{a}$ & $<0.0001$ & 0.0012 & 0.3 \\
\hline \multicolumn{8}{|l|}{ Plasma inflammatory markers } \\
\hline $\mathrm{IL}-6(\mathrm{pg} / \mathrm{mL})(n=7-8)$ & $3.40 \pm 0.48^{a}$ & $3.63 \pm 0.27^{\mathrm{a}}$ & $1.82 \pm 0.19^{b}$ & $3.91 \pm 0.56^{a}$ & 0.0004 & 0.0112 & $<0.0001$ \\
\hline TNF-alpha $(\mathrm{pg} / \mathrm{mL})(n=7-8)$ & $1.08 \pm 0.34^{b}$ & $1.20 \pm 0.16^{b}$ & $1.13 \pm 0.20^{b}$ & $1.83 \pm 0.39^{a}$ & 0.0448 & 0.13 & 0.7465 \\
\hline $\mathrm{CRP}, \mathrm{mg} / \mathrm{L}(n=5-8)$ & $0.26 \pm 0.04^{b}$ & $0.21 \pm 0.004^{b}$ & $0.34 \pm 0.07^{a}$ & $0.13 \pm 0.02^{b}$ & 0.006 & $<0.0001$ & 0.6422 \\
\hline
\end{tabular}

Each value is a mean \pm S.E.M. Number of repetitive experiments indicated within parenthesis. Means within a row with unlike superscripts letters a, b, $c$ d differ significantly $(p<0.05)$. CS, corn starch diet; CRP, corn starch + red pitaya juice; HCHF, high-carbohydrate, high-fat diet; HRP, high-carbohydrate, high-fat diet + red pitaya juice 


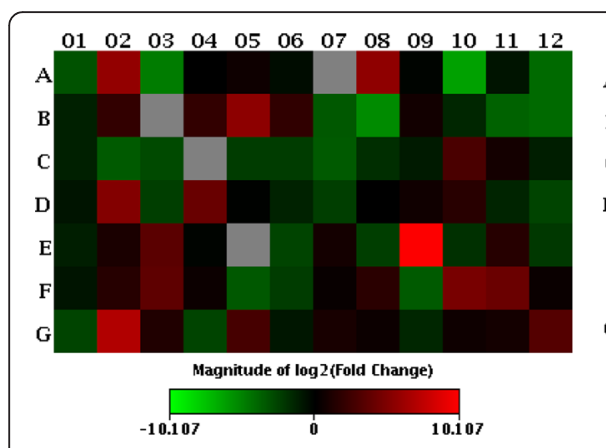

a. CS vs. HCHF

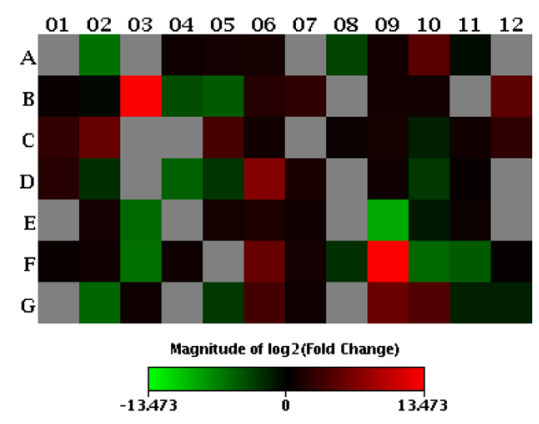

b. CS vs.CRP

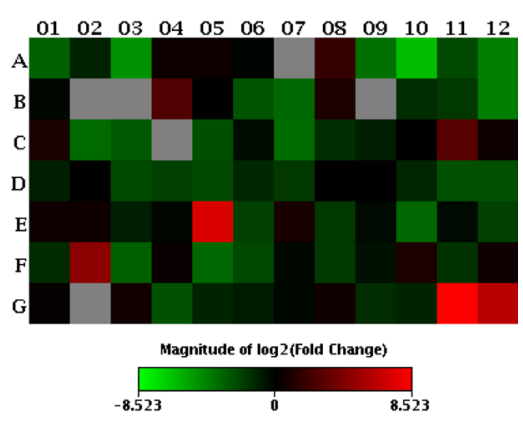

c. HCHF vs.HRP

d. PCR array gene table

\begin{tabular}{|l|l|l|l|l|l|l|l|l|l|l|l|l|}
\hline & & 1 & 2 & 3 & 4 & 5 & 6 & 7 & 8 & 9 & 10 & 11 \\
\hline A & Adcyap1 & Adcyap1r1 & Adipoq & Adipor1 & Adipor2 & Adra2b & Adrb1 & Agrp & Apoa4 & Atrn & Bdnf & Brs3 \\
\hline B & C3 & Calca & Calcr & Cartpt & Cck & Cckar & Clps & Cnr1 & Cntf & Cntfr & Crh & Crhr1 \\
\hline C & Drd1 & Drd2 & Gal & Galr1 & Gcg & Gcgr & Gh1 & Ghr & Ghrl & Ghsr & Glp1r & Grp \\
\hline D & Grpr & HcRt & Hcrtr1 & Hrh1 & Htr2c & Iapp & Il1a & Il1b & Il1r1 & Il6 & Il6r & Ins1 \\
\hline E & Ins2 & Insr & Lep & Lepr & Mc3r & Mchr1 & Nmb & Nmbr & Nmu & Nmur1 & Npy & Npy1r \\
\hline F & Nr3c1 & Ntrk1 & Nts & Ntsr1 & Oprk1 & Oprm1 & Pomc & Ppara & Pparg & Ppargc1a & Prlhr & Ptpn1 \\
\hline G & Pyy & Ramp3 & Sigmar1 & Sort1 & Sst & Sstr1 & Thrb & Tnf & Trh & Trhr & Ucn & Ucp1 \\
\hline H & Actb & B2m & Hprt1 & Ldha & Rplp1 & RGDC & RTC & RTC & RTC & PPC & PPC & PPC \\
\hline
\end{tabular}

Fig. 1 The changes in obesity-related genes among the controls, CRP and HRP groups. The heat map demonstrating fold regulation expression data between CS group and HCHF group (a), CS group and CRP group (b) and HCHF group and HRP group (c). $\mathbf{d}$ shows representative PCR array gene table

expression data for all the genes between CS and HCHF groups, CS and CRP groups and HCHF and HRP groups. Table 3 presents the fold regulation of the selected genes from HCHF, HRP, CS and CRP groups that gave reproducible results. In HCHF-fed rats, four genes were downregulated namely complement component 3 (C3), ciliary neurotrophic factor receptor (Cntfr), glucagon receptor (Gcgr) and interleukin 1 alpha (IL-1 $\alpha$ ) while three genes were up-regulated which are insulin receptor (Insr), neuropeptides Y (Npy) and Sigma non-opioid intracellular receptor 1 (Sigmar1) and four genes namely Apolipoprotein AIV (Apoa4), Interleukin 1 receptor, type 1 (IL-1r1), Proopiomelanocortin (Pomc), and Thyroid hormone receptor beta (Thrb) showed no changed as compared to CS group (Table 3). Nevertheless, only the expression level Cntfr, IL$1 \alpha$ and IL-1r1 were significantly different $(p<0.05)$ compared to CS group (Fig. 2). Corn starch-fed supplemented rats (CRP group) significantly decreased $(p<0.05)$ the expression of Cntfr and IL-1 $\alpha$ (Fig. 3). Supplementation of red pitaya juice for eight weeks resulted in up-regulation of Insr and Pomc in HRP group compared to HCHF group (Table 3). However, the difference showed no statistical significance $(p>0.05)$ (Fig. 4).

\section{Discussion}

The present study evaluated the red pitaya-targeted genes in high-carbohydrate, high-fat diet-induced metabolic syndrome rats using polymerase chain reaction
Table 3 Fold regulations of detected genes from HCHF, HRP, CS and CRP groups

\begin{tabular}{|c|c|c|c|}
\hline \multirow[t]{2}{*}{ Gene } & \multicolumn{3}{|c|}{ Fold regulation } \\
\hline & CS vs. HCHF & CS vs. CRP & HCHF vs. HRP \\
\hline Adipor1 & ND & 1.32 & 1.67 \\
\hline Apoa4 & -1.13 & -13.15 & 1.89 \\
\hline $\mathrm{C} 3$ & -2.47 & -1.19 & 1.43 \\
\hline Cnr1 & ND & 1.92 & ND \\
\hline Cntfr & $-2.79^{*}$ & $-2.82^{*}$ & ND \\
\hline Gcgr & -5.17 & -1.31 & 1.74 \\
\hline Ghr & ND & -2.85 & ND \\
\hline$I L-1 a$ & $-5.55^{*}$ & $-3.60^{*}$ & ND \\
\hline $\mid \mathrm{L}-1 \mathrm{r} 1$ & $1.53^{*}$ & 1.02 & 1.67 \\
\hline Insr & 2.01 & 1.37 & 2.09 \\
\hline Npy & 2.79 & ND & 1.54 \\
\hline Pomc & 1.24 & -1.20 & 2.09 \\
\hline Sigmar1 & 2.43 & 1.55 & 1.62 \\
\hline Thrb & 1.95 & -1.16 & 1.62 \\
\hline
\end{tabular}

$\mathrm{CS}$, corn starch diet; CRP, corn starch + red pitaya juice; $\mathrm{HCHF}$, highcarbohydrate, high-fat diet; HRP, high-carbohydrate, high-fat diet + red pitaya juice

*indicate significant difference at $p<0.05$

ND; non-detected genes 


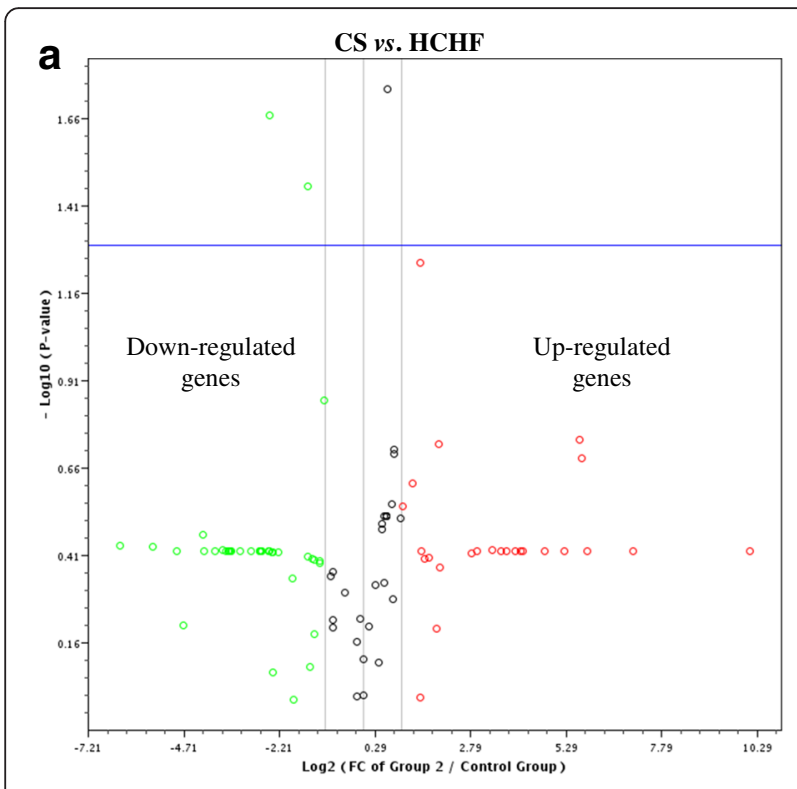

b

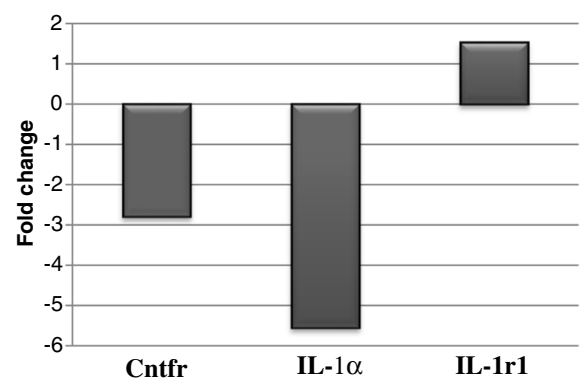

Fig. 2 The changes of obesity-related genes from HCHF and CS groups. a The volcano plot demonstrating statistical significance versus fold regulation expression data between the HCHF group and the CS group. The blue line indicates $p$-value, set at 0.05. b Genes with significant differences $(p<0.05)$ between the two groups are presented in the histogram. CS, corn starch diet; HCHF, high-carbohydrate, high-fat diet; Cntfr, ciliary neurotrophic factor receptor; IL-1 a, Interleukin 1 alpha; IL-1r1, Interleukin 1 receptor, type I

(PCR) array in order to elucidate the molecular mechanism underlying the physiological responses. PCR array combines real-time PCR sensitivity and the ability of microarrays to detect the expression of many genes simultaneously [13]. This new technique of evaluating gene expression allows the expression levels of disease- or pathway-focused genes and provides reliable method, easy-to-use and is highly sensitive [14]. Up to now, quantitative RT-PCR arrays have had limited use to study nutrient-related interventions [15], maternal perinatal under-nutrition $[16,17]$ and brown adipose tissue metabolism [18], probably because of high cost despite the improved sensitivity.

Analysis from the present study revealed that several obesity-related genes change in HCHF groups, which further confirmed the development of this metabolic syndrome rat model. In obese rats, four genes were down-regulated (C3, Cntfr, Gcgr, IL-1 $\alpha$ ) while three genes were up-regulated (Insr, Npy and Sigmar1) and five genes (Adipor1, Apoa4, IL-r1, Pomc, Thrb) showed no change compared to CS group. However, among these, only Cntfr, IL-1 $\alpha$ and IL-1r1 showed significant changes which might be due to large variations of the expression levels of other genes within the groups. IL- $1 \alpha$ and IL-1r1 are classified as anorectic genes. The appetite suppressing effects of these two genes (IL- $1 \alpha$ and IL1r1) might be associated with fever, increased thermogenesis and reduced food intake due to inflammation and injury [19]. Interleukin- $1 \alpha$ is cytokine of the interleukin-1 family (IL-1) which is a key mediator of inflammation, located on the long arm of human chromosome 2 [20]. IL-1 family also composed of IL-1 $\beta$ that exerts almost identical biological activities with IL- $1 \alpha$ by binding to IL-1 type 1 receptor (IL-1r1). However, IL-1 $\beta$ does not occur in healthy subjects. In contrast, IL- $1 \alpha$ is present at constitutive levels in primary cells such as hepatocytes and epithelial cells [21]. IL- $1 \alpha$ forms heterodimeric complexes that induce inflammation when bound to the IL-1r1. The negative regulator of inflammation is IL-1 receptor antagonist (IL-1Ra) [18].

García et al. [19] showed that knockout of the gene coding for IL-1r1 resulted in mature-onset obesity due to reduced fat utilization, decreased locomotor activity and reduced leptin sensitivity. Data from our previous study indicated that body weight of HCHF-fed rats were significantly higher than CS-fed rats [10] despite the same expression level of IL-1r1. Possibly, other genes play role in increasing body weight of $\mathrm{H}$-fed rats but not IL-1r1. Furthermore, serum amyloid A protein, an inflammatory marker in atherosclerosis, was reduced despite higher total cholesterol concentrations in IL- $1 \alpha$ deficient mice fed with high-fat diet [22]. Similarly, the present study showed the expression level of IL-1 $\alpha$ was significantly reduced in line with the decreased inflammatory markers of interleukin-6 in HCHF-fed rats compared to CS group. The relationship between inflammation and obesity is well established $[23,24,25]$. It is interesting to point out that the contradictory results obtained from the present study might be due to increased inflammation in control rats without high-fat diet probably due to enhance glucose intake after meal as reported by Gregerson et al. [26]. Importantly, these results explained the condition whereby the appetite suppressing effect of IL- $1 \alpha$ was altered resulting in increased food intake, and hence increased body weight of $\mathrm{H}$-fed rats. Recently, Dinarello and Netea [27] postulated that IL- $1 \alpha$ deficient mice had reduced aortic lesion size due to the transferred of hematopoietic cells from the bone marrow. However, the aortic lesion was not measured in the present study, so the effect of IL- $1 \alpha$ downregulation on the aortic lesion size was not known. 

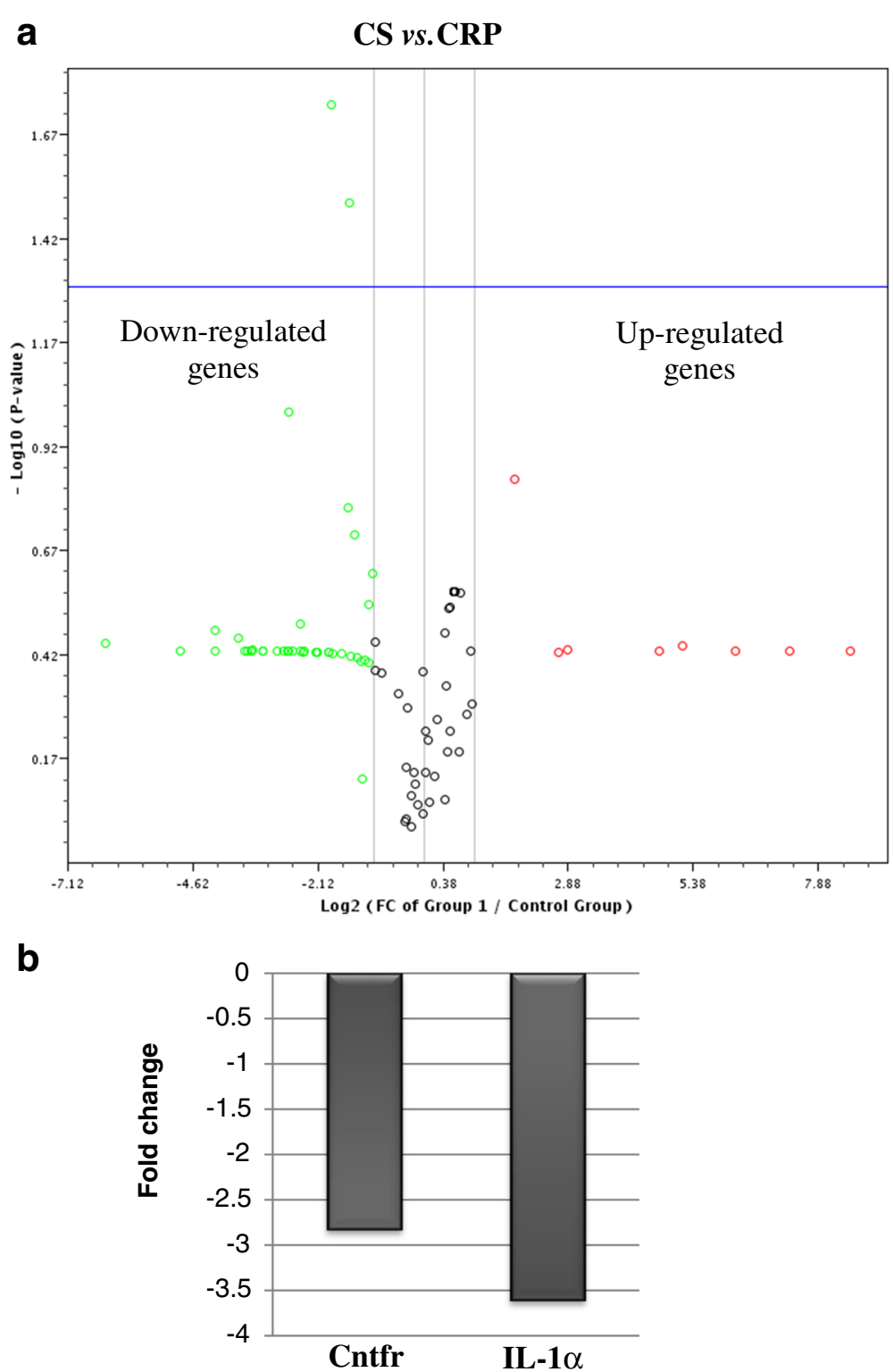

Fig. 3 The changes of obesity-related genes from CS and CRP groups. a The volcano plot demonstrating statistical significance versus fold regulation expression data between the CS group and the CRP group. The blue line indicates $p$-value, set at 0.05 . $\mathbf{b}$ Genes with significant differences $(p<0.05)$ between the two groups are presented in the histogram. CS, corn starch diet; CRP, corn starch + red pitaya juice; Cntfr, ciliary neurotrophic factor receptor; IL-1 a, Interleukin 1 alpha

Cntfr, Gcgr and Insr are anorectic genes, Sigmar1 and Npy are orexigenic genes and C3 is the gene that relate to energy expenditure. Although there were no statistically significant for these genes between the HCHF group and CS group except for Cntfr, it is important to understand the changes of obesity-related genes as a first critical step towards evaluating this metabolic syndrome rat model at the molecular level. The role of C3 in obesity-related metabolic diseases has been recognized as it stimulates the accumulation of triglyceride, promotes the uptake of glucose and reduces the release of free fatty acids [28]. Besides, the up-regulation of C3 impaired energy expenditure and food intake via its action on the central nervous system [29]. It is fascinating that the $\mathrm{C} 3$ expression decreases with obesity in the present study given that C3 mRNA expression levels typically positively correlated with obesity. Nevertheless, this finding is in agreement with recent discovery by Gupta et al. [30] whereby they found down-regulation of complement C3 in subcutaneous tissue of obese women.

Cntfr reduces food intake and increase energy expenditure by directly induces the transcription of Pomc genes 


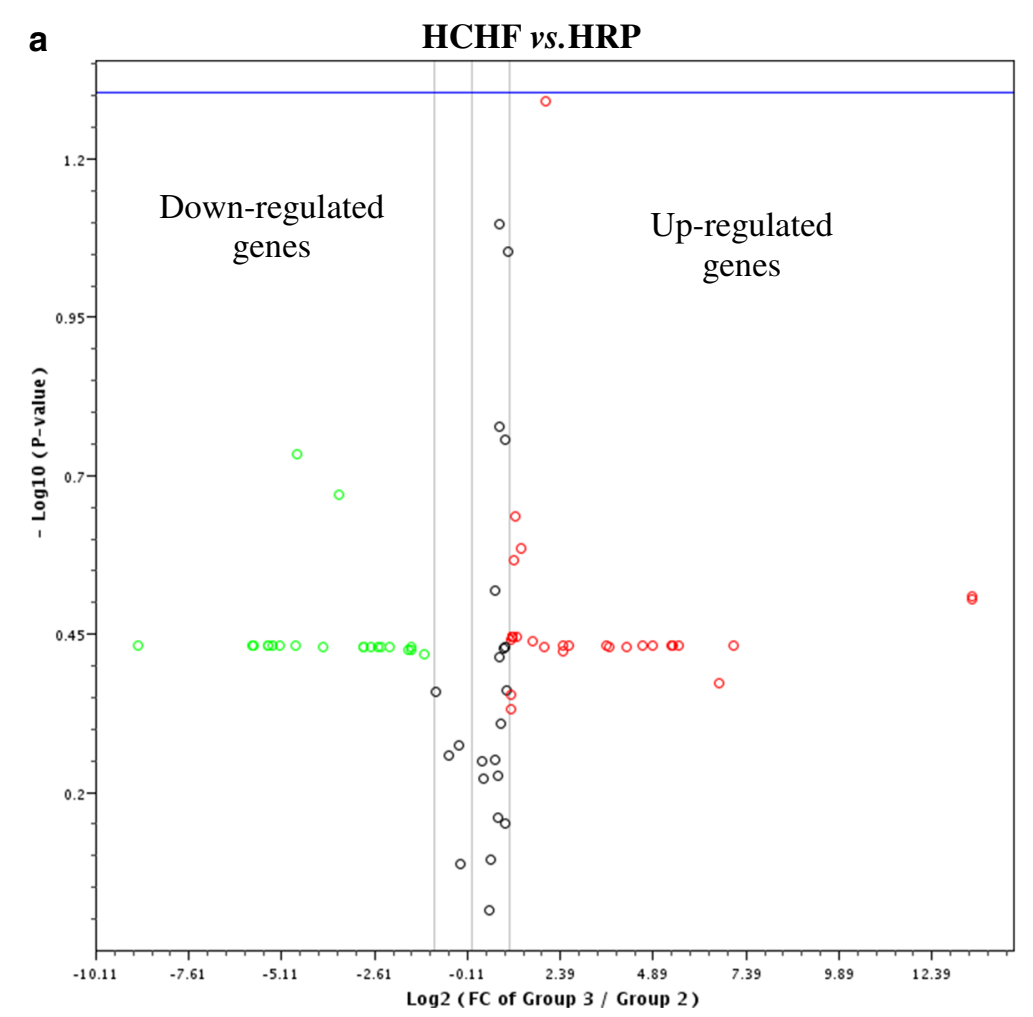

Fig. 4 The changes of obesity-related genes from HCHF and HRP groups. a The volcano plot demonstrating statistical significance versus fold regulation expression data between the HCHF group and the HRP group. The blue line indicates $p$-value, set at 0.05 . None of the genes for this group is significantly different at $p<0.05$. HCHF, high-carbohydrate, high-fat diet; HRP, high-carbohydrate, high-fat diet + red pitaya juice

[31, 32]. Therefore, the absence of this protective factor against high-carbohydrate, high-fat diet resulted in weight gain and obesity. Gcgr is a receptor for glucagon which mediated the process of glycogenolysis, lipolysis, ketogenesis and gluconeogenesis. Following carbohydrate-rich meal, the expression level of Gcgr is significantly decreased [5], which is in agreement with the present study. Furthermore, the increased in Npy and Sigmar1 gene expression further supported this obesity rat model. Npy is part of the hypothalamic melanocortin pathway that regulates the central energy metabolism [33]. Previous study has demonstrated the increased in Npy expression stimulated food intake and hence resulted in weight gain [34]. Similarly, obese individual with non-alcoholic fatty liver diseases was found to have up-regulation of opioid signalling including Sigmar1 [35]. On the other hand, the expression level of Insr was up-regulated. Insr, the heterodimer genes coding for insulin signalling members, have been reported to be significantly reduced in obesity [36]. Thus, the up-regulation of Insr in the present study may lead to feedback down-regulation to reduce food intake due to increasing body weight of $\mathrm{H}$-fed rats. The exact mechanism, however, is unknown.

There was report that bioactive compounds and nutrients in food can interact with the genome by highly complex forms [37]. For instance, administration of oleic acid through intracerebroventricular was found to decrease body weight by reduction of Npy and increase Pomc neuron [38]. Additionally, Lu et al. [15] found that supplementation of green tea polyphenols in high-fat induced obese rats reduced body weight through mediating obesity-related genes. In the present study, the expression of Insr and Pomc increased in obese rats supplemented with red pitaya while no changes were observed in seven genes (Adipor1, Apoa4, C3, Gcgr, IL-1r1, Insr, Npy, Pomc, Sigmar1 and Thrb). There was no statistical significance between the HRP group and $\mathrm{H}$ group that warrant future research with bigger sample size. Insulin plays critical roles in energy functions particularly in carbohydrate and lipid metabolism. Obese individual usually has marked declined in insulin levels [5]. Thus, the increased gene expression level of Insr in HRP group indicating that red pitaya ameliorates the deficiency or resistant of insulin in obese rats. Meanwhile, Pomc is important for central regulation of energy balance whereby it reduce food intake and increase energy expenditure via the release of $\alpha$ melanocyte-stimulating hormone (MSH) and activation of melanocortin receptors [39].

In addition, CRP group revealed the decreased expression of anorectic genes, Apoa4, Cntfr, Ghr and IL- $1 \alpha$. 
Among these, only IL-1 $\alpha$ and Cntfr provides a significant reduction. As mentioned before, the increase expression of IL- $1 \alpha$ and Cntfr induce satiety which in turn reduce the food intake and promote weight loss. Ghr plays a critical role in lipolysis, adipogenesis and lipogenesis and lower Ghr expression in the adipocyte is associated with obesity [40]. Likewise, Apoa4 triggered the satiety signal through dietary fat [41] and the decreased gene expression level of Apoa4 contributed to weight gain [15]. These findings confirmed that the lean control rats in the present study were more sensitive to the palatability of red pitaya juice as compared to high-carbohydrate, high-fat diet-induced obese rats. Red pitaya juice is an example of palatable foods that inhibit the satiety signals and hence increasing the food intake of CRP rats. Red pitaya juice contains higher amount of energy-supplying macronutrients causing progressive increment in body weight, and total body fat throughout the intervention period. This could explained the increased in abdominal fat deposition in CRP rats in the absence of a high carbohydrate, high fat diet.

As discussed earlier, the analysis on the obesity-related genes after supplementation with red pitaya juice resulted in the detection of 14 genes. The remaining 70 genes were not detected in the liver samples of all the three groups. The likely reasons for this condition are those undetected genes were weakly expressed or not expressed at all in the liver tissues. For instance, Calcr is typically expressed in the kidney and brain, Cartpt is normally expressed in the spinal cord, testis, prostate and brain while Brs3 is normally detected in the testis, kidney and brain [42]. Moreover, Lu et al. [15] suggested that the gene array may have limitation in the sensitivity of the detection. The authors also proposed that the changes in gene expression might not be detected in the mixture of cell types in tissue samples.

Interestingly, data showed that supplementation of red pitaya juice decreased the circulating $\mathrm{C}$-reactive protein (CRP), thus reducing the diet-induced low grade inflammation in-vivo. A possible explanation for this might be that red pitaya supplementation reduced CRP concentration by reducing its production rate without altering the liver genes. Mauger et al. [43] reported that the main determinant for CRP concentration is its production rate which showed significant association with metabolic syndrome characteristics. In contrast, a recent study on the mechanism of CRP reduction by statins, a drug used for the treatment of hypercholesterolemia, indicated that its production was not reduced but the fractional catabolic rate was enhanced [44]. It is speculated that the increased in pro-inflammatory cytokines (IL-6 and TNFalpha) was due to increase in liver fat as supplementation of red pitaya added to total energy content in high carbohydrate, high fat diet. Although the secretion of IL6 regulates the induction of CRP in hepatocytes [45], the present study found contradicts results. As red pitaya supplementation increased IL-6, plasma concentration of CRP was reduced. In agreement with the present study, Malavazos et al. [46] found no positive association between IL- 6 and CRP. In fact, a recent study reported that the intake of statin lowered CRP concentration but the study found no association between statin use and other inflammatory cytokines especially IL-6, TNF- $\alpha$, and IL-1 $\beta$ [47].

\section{Conclusions}

In summary, the present results demonstrated that genetic mechanisms play a major role in determining body weight by controlling energy balance homeostasis. The present study provides striking results in that the changes in anorectic, orexigenic and energy expenditure related genes not only to advance the understanding of beneficial effects of red pitaya, but the usefulness of this diet-induced rat model. However, the overall effects of red pitaya supplementation are still controversial as inconsistent results were obtained. Longer duration of study may be required. Furthermore, it is important to highlight the complexity of energy balance homeostasis that may be time-specific, and/or tissue- and species specific [48]. Nevertheless, the changes in anorectic, orexigenic and energy expenditure related genes observed in the present study provide the salient and novel findings for obesity research. This work can be further extended to investigate possible therapeutic effects of red pitaya supplementation on metabolic syndrome patient which will in turn help to fight against the obesity epidemic.

\section{Abbreviations}

Actb, actin, beta; Adipor1, adiponectin receptor 1; Apoa4, apolipoprotein A-IV; Brs3, bombesin-like receptor 3; C3, complement component 3; Calcr, calcitonin receptor; Cartpt, CART prepropeptide; cDNA, complementary DNA; Cntfr, Ciliary neurotrophic factor receptor; CRP, corn starch + red pitaya juice; CRP, C-reactive protein; CS, corn starch diet; CT, threshold cycle; DNA, deoxyribonucleic acid; ELISA, enzyme-linked immunosorbent assays; Gcgr, glucagon receptor; gDNA, genomic deoxyribonucleic acid; Ghr, growth hormone receptor; HCHF, high carbohydrate, high fat; Hprt1, hypoxanthine phosphoribosyltransferase 1; HRP, high fat diet + red pitaya juice; IL-1, interleukin 1; IL-1r1, interleukin 1 receptor, type I; IL-1a, interleukin 1 alpha; IL-1 $\beta$, interleukin 1 beta; IL-6, interleukin 6, Insr, insulin receptor; Ldha, lactate dehydrogenase $A ;$ mRNA, messenger ribonucleic acid; MSH, melanocyte-stimulating hormone; NPY, neuropeptide Y; PCR, polymerase chain reaction; Pomc, proopiomelanocortin; RNA, ribonucleic acid;Rpl13a, ribosomal protein L13A; Rplp1, ribosomal protein, large, P1; RT, reverse transcription; SEM, standard error of mean; Sigmar1, sigma non-opioid intracellular receptor 1; Thrb, thyroid hormone receptor beta; Tnf, tumor necrosis factor

\section{Acknowledgements}

We thank Professor Lindsay Brown, Dr. Hemant Poudyal and Dr Sunil Panchal, University of Southern Queensland, Toowoomba, Australia for their assistance with the in-vivo study. We thank Malaysia Genome Institute (Microarray) for providing the bio analyzer analysis.

\section{Funding}

This study was supported by the Universiti Putra Malaysia (UPM) through Research University Grant Scheme (RUGS) (04-02-12-1759RU). 


\section{Availability of data and material}

Data are all contained within the paper.

\section{Authors' contributions}

NSR PI AR conceived and designed the experiments. NSR performed the experiments. NSR PI AR analyzed the data. PI and AR contributed reagents/ materials/analysis tools. NSR PI AR wrote the paper. All authors read and approved the final manuscript.

\section{Competing interests}

The authors declare that they have no competing interests.

\section{Consent for publication}

Not applicable.

\section{Ethics approval and consent to participate}

All the experimental protocols were approved by the Animal Experimentation Ethics Committee of The University of Southern Queensland under the guidelines of the National Health and Medical Research Council of Australia.

\section{Author details}

'Department of Food Science, Universiti Putra Malaysia, Serdang, Selangor 43400, Malaysia. ${ }^{2}$ Department of Biomedical Science, Universiti Putra Malaysia, Serdang 43400, Malaysia. ${ }^{3}$ Department of Nutrition and Dietetics, Universiti Putra Malaysia, Serdang 43400, Malaysia.

Received: 1 February 2016 Accepted: 7 July 2016

Published online: 26 July 2016

\section{References}

1. Youngson NA, Morris MJ. What obesity research tells us about epigenetic mechanisms. Phil Trans R Soc B. November 2012;2013(368).

2. Spiegelman BM, Flier JS, Israel B, Medical D. Obesity and the Regulation of Energy Balance. Cell. 2001;104:531-43.

3. Hill JO, Wyatt HR, Peters JC, Hill JO, Wyatt HR, Peters JC. Energy Balance and Obesity Energy Balance: Definitions. J Am Heart Assoc. 2012;126:126-32.

4. Faroogi IS. Genetic, molecular and physiological insights into human obesity. Eur J Clin Investig. 2010;41 suppl 4:451-5.

5. Harvey R, Ferrier D. Lippincott's llustrated Reviews: Biochemistry. Pennsylvania: Wolters Kluwer Health: Lippincott Williams and Wilkins; 2011.

6. Egecioglu E, Skibicka KP, Hansson C, Alvarez-crespo M, Friberg PA, Jerlhag E, et al. Hedonic and incentive signals for body weight control. Rev Endocrinol Metab Disord. 2011;12:141-51.

7. Esquivel P, Stintzing FC, Carle R. Phenolic compound profiles and their corresponding antioxidant Capacity of purple pitaya (Hylocereus sp.) genotypes. J Biosci. 2007;62(9-10):636-44.

8. Mohd Adzim Khalili R, Norhayati AH, Rokiah MY, Asmah R, Siti Muskinah M, Abdul Manaf A. Hypocholestrolemic effect of red pitaya (Hylocereus sp.) on hypercholesterolemia induced rats. Int Food Res J. 2009;16:431-40.

9. Omidizadeh A, Yusof RM, Ismail A, Roohinejad S, Nateghi L, Zuki M, et al. Cardioprotective compounds of red pitaya (Hylocereus polyrhizus) fruit. J Food Agric Environ. 2011;9:152-6.

10. Ramli NS, Brown L, Ismail P, Rahmat A. Effects of red pitaya juice supplementation on cardiovascular and hepatic changes in highcarbohydrate, high-fat diet-induced metabolic syndrome rats. BMC Complement Altern Med. 2014;14:189.

11. Panchal SK, Poudyal H, Arumugam TV, Brown L. Rutin Attenuates Metabolic Changes, Nonalcoholic Steatohepatitis, and Cardiovascular Remodeling in High-carbohydrate, high-fat Fed Rats. J Nutr. 2011;141 Suppl 20:1062-9.

12. Poudyal H, Panchal S, Brown L. Comparison of purple carrot juice and $\beta$-carotene in a high-carbohydrate, high-fat diet-fed rat model of the metabolic syndrome. Br J Nutr. 2010;104 Suppl 9:1322-32.

13. SABiosciences. RT ${ }^{2}$ Profiler ${ }^{T M}$ PCR Array. 2014. http://www.sabiosciences.com/ PCRArrayPlate.php. Accessed 15 June 2014.

14. Yan-fang T, Dong W, Li P, Wen-li Z, Jun L, Na W, Jian W, Xing F, Yin-Hong L, Jian N, Jian P. Analyzing the gene expression profile of pediatric acute myeloid leukemia with real-time PCR arrays. Cancer Cell Int. 2012;12(1):1.

15. Lu C, Zhu W, Shen C-L, Gao W. Green tea polyphenols reduce body weight in rats by modulating obesity-related genes. PLoS One. 2012;7(6):e38332.

16. Lukaszewski M, Mayeur S, Fajardy I, Delahaye F, Dutriez-casteloot I, Montel V, Dickes-coopman A, Laborie C, Lesage J, Vieau D, Breton C. Maternal prenatal undernutrition programs adipose tissue gene expression in adult male rat offspring under high-fat diet. Am J Physiol Endocrinol Metab. 2011;3:548-59.

17. Delahaye F, Lukaszewski M, Wattez J, Cisse O, Dutriez-casteloot I, Fajardy I, Montel V, Chopmann AD, Laborie C, Lesage J, Breton C, Vieau D. Maternal perinatal undernutrition programs a " brown-like " phenotype of gonadal white fat in male rat at weaning. Am J Physiol Regul Integr Comp Physiol. 2010;299(2):101-10.

18. Bauwens JD, Schmuck EG, Lindholm CR, Ertel RL, Mulligan JD, Hovis I, Viollet B, Saupe KW. Cold tolerance, cold-induced hyperphagia, and nonshivering thermogenesis are normal in a 1 -AMPK ${ }^{-}$- mice. Am J Physiol Regul Integr Comp Physiol. 2011;301:473-83.

19. García MC, Wernstedt I, Berndtsson A, Enge M, Bell M, Hultgren O, Horn M, Ahren B, Enerbeck S, Ohlssen C, Wallenius V, Jansson JO. Mature-Onset Obesity in Interleukin-1 Receptor I Knockout Mice. Diabetes. 2006;55:1205-13.

20. Curti MLR, Borges MC, Rogero MM, Ferreira SRG. Studies of Gene Variants Related to Inflammation, Oxidative Stress, Dyslipidemia, and Obesity: Implications for a Nutrigenetic Approach. J Obes. 2011;2011:497401.

21. Veerdonk FL, Van D, Netea MG. New insights in the immunobiology of IL-1 family members. Front Immunol. 2013;4:1-11.

22. Kamari Y, Werman-venkert R, Shaish A, Werman A, Harari A, Gonen A, Voronov E, Grosskopfa I, Shaeabib Y, Grossmanb E, Iwakurae Y, Dinarello CA, Aptec RN, Harats D. Differential role and tissue specificity of interleukin-1a gene expression in atherogenesis and lipid metabolism. Atherosclerosis. 2007;195:31-8.

23. Rocha VZ, Libby P. The Metabolic Syndrome and Atherogenesis. In: Grundy SM, editor. Atlas of Atherosclerosis and Metabolic Syndrome. New York Dordrecht Heidelberg London: Springer; 2011. p. 45-58.

24. Maury E, Brichard SM. Adipokine dysregulation, adipose tissue inflammation and metabolic syndrome. Mol Cell Endocrinol. 2010;314 Suppl 1:1-16.

25. Shoelson SE, Lee J, Goldfine AB. Review series Inflammation and insulin resistance. J Clin Investig. 2006;116 Suppl 7:1793-801.

26. Gregersen S, Heilbronn LK, Campbell LV. Inflammatory and Oxidative Stress Responses to High-Carbohydrate and High-Fat Meals in Healthy Humans. J Nutr Metab. 2012;1-8.

27. Dinarello CA, Netea MG. The Interleuki-1 Family: Role in inflammation and diseases. In Yoshimoto T, Yoshimoto T, editors. Cytokine Frontiers:Regulation of immune responses in health and diseases. London: Springer Tokyo Heidelberg New York Dordrecht; 2014. pp. 3-52.

28. Phieler J, Garcia-martin R, Lambris JD, Chavakis T. Seminars in Immunology. The role of the complement system in metabolic organs and metabolic diseases. Semin Immunol. 2013;25(1):47-53.

29. Wei J, Lin C, Chiang C, Carter AM. Obesity and clustering of cardiovascular disease risk factors are associated with elevated plasma complement $\mathrm{C} 3$ in children and adolescents. Pediatr Diabetes. 2012;13:476-83.

30. Gupta A, Rezvani R, Lapointe M, Poursharifi P, Marceau P, Tiwari S. Downregulation of Complement C3 and C3aR Expression in Subcutaneous Adipose Tissue in Obese Women. PLoS One. 2014;9 Suppl 4:1-9.

31. Couvreur O, Aubourg A, Crépin D, Degrouard J, Gertler A, Taouis M, Vacher C. The anorexigenic cytokine ciliary neurotrophic factor stimulates POMC gene expression via receptors localized in the nucleus of arcuate neurons. Am J Physiol Endocrinol Metab. 2012;302(57):458-67.

32. Vacher C, Aubourg A, Couvreur O, Bailleux V, Nicolas V, Cre D. A putative physiological role of hypothalamic CNTF in the control of energy homeostasis. FEBS Lett. 2008;582:3832-8.

33. Jeong JK, Jae J, Kim JG, Lee BJ. Participation of the central melanocortin system in metabolic regulation and energy homeostasis. Cell Mol Life Sci. 2014;71 Suppl 19:3799-809.

34. Montgomery IA, Irwin N, Flatt P. Beneficial Effects of (pGlu-GIn) -CCK-8 on Energy Intake and Metabolism in High Fat Fed Mice are Associated with Alterations of Hypothalamic Gene Expression. Hormonal Metab Res. 2013;45:471-3.

35. Mehta R, Birerdinc A, Wang L, Younoszai Z, Moazzez A, Elariny H, Goodman Z, Chandhoke Baranova A, Younossi ZM. Expression of energy metabolism related genes in the gastric tissue of obese individuals with non-alcoholic fatty liver disease. BMC Gastroenterol. 2014;14 Suppl 1:1-9.

36. Nteeba J, Ross JW, li JWP, Keating AF. High fat diet induced obesity alters ovarian phosphatidylinositol-3 kinase signaling gene expression. Reprod Toxicol. 2013:42:68-77.

37. Choi S, Friso S. Epigenetics: A New Bridge between Nutrition and Health. Adv Nutr. 2010;1:8-16.

38. Schwinkendorf DR, Tsatsos NG, Gosnell BA, et al. Effects of central administration of distinct fatty acids on hypothalamic neuropeptide expression and energy metabolism. Int J Obes (Lond). 2011;35:336-44. 
39. Cansell $C$, Luquet $\mathrm{S}$. Hypothalamic regulation of energy balance : a key role for DICER miRNA processing in arcuate POMC neurons. Mol Metab. 2013;2 Suppl 2:55-7.

40. Erman A, Veilleux A, Tchernof A, Goodyer CG. Human growth hormone receptor (GHR) expression in obesity: I.GHR mRNA expression in omental and subcutaneous adipose tissues of obese women. Int J Obes. 2011;35(12):1511-9.

41. Fujimoto K, Fukagawa K, Sakata T, Tso P. Suppression of food intake by apolipoprotein A-IV is mediated through the central nervous system in rats. J Clin Investig. 1993;91:1830-3.

42. Feng Y, Guan X, Li J, Metzger JM, Zhu Y, Juhl K, Zhang BB, Thornberry NA, Reitman ML, Zhou, YP. Bombesin Receptor Subtype-3 (BRS-3) Regulates Glucose-Stimulated Insulin Secretion in Pancreatic Islets across Multiple Species. Endocrinology. 2011;2011(3 Suppl):4106-15.

43. Mauger JF, Levesque J, Paradis ME, Bergeron N, Tchemof A, Couture P, Lamarche B. Intravascular Kinetics of C-Reactive Protein and Their Relationships with Features of the Metabolic Syndrome. J Clin Endocrinol Metabol. 2008:93:3158-64.

44. Thongtang N, Diffenderfer MR, Ooi EMM, Asztalos BF, Dolnikowski GG, Lamon-fava S, Schaefer EJ. Effects of atorvastatin on human C-reactive protein metabolism. Atherosclerosis. 2013;226 Suppl 2:466-70

45. Terra $X$, Montagut $G$, Bustos $M$, Llopiz N, Ardèvol A, Bladé $C$, Fernándezlarrea J, Pujadas G, Salvadó J, Arola L. Grape-seed procyanidins prevent lowgrade inflammation by modulating cytokine expression in rats fed a highfat diet. J Nutr Biochem. 2009;20 Suppl 3:210-8.

46. Malavazos AE, Corsi MM, Ermetici F, Coman C, Sardanelli F, Rossi A, Morricone L, Ambrosi B. Proinflammatory cytokines and cardiac abnormalities in uncomplicated obesity: relationship with abdominal fat deposition. Nutr Metab Cardiovasc Dis. 2007;17 Suppl 4:294-302.

47. Lyngdoh T, Vollenweider P, Waeber G, Marques-Vidal P. Association of statins with inflammatory cytokines: a population-based Colaus study. Atherosclerosis. 2011;219 Suppl 1:253-8.

48. Baboota RK, Murtaza N, Jagtap S, Singh DP, Karmase A, Kaur J, Bhutani KK, Boparaid RK, Premkumare LS, Kondepudia KK, Bishnoi M. Capsaicin-induced transcriptional changes in hypothalamus and alterations in gut microbial count in high fat diet fed mice. J Nutr Biochem. 2014;25:893-902.

\section{Submit your next manuscript to BioMed Central and we will help you at every step:}

- We accept pre-submission inquiries

- Our selector tool helps you to find the most relevant journal

- We provide round the clock customer support

- Convenient online submission

- Thorough peer review

- Inclusion in PubMed and all major indexing services

- Maximum visibility for your research

Submit your manuscript at www.biomedcentral.com/submit

C) Biomed Central 